\title{
Left ventricular inflow propagation velocity for diastolic function testing: head-to-head comparison between velocity-encoded MRI and color M-mode Doppler echocardiography
}

\author{
Pieter J van den Boogaard ${ }^{1}$, Nina Ajmone Marsan², Jeroen J Bax², Albert de Roos ${ }^{1}$, Jos J Westenberg ${ }^{1 *}$ \\ From 16th Annual SCMR Scientific Sessions \\ San Francisco, CA, USA. 31 January - 3 February 2013
}

\section{Background}

The inflow propagation velocity (Vprop) of the early filling wave has been proposed as an accurate marker of left ventricular (LV) diastolic function [1]. Traditionally, Color M-mode echo Doppler is used for Vprop-assessment. However, this method has not been validated against an alternative modality such as velocity-encoded (VE) MRI for assessing Vprop. The purpose of this study was to compare Vprop assessed from high temporal VE MRI with Color M-mode echo Doppler in patients with ischemic cardiomyopathy.

\section{Methods}

In 36 patients (mean age $60 \pm 12$ years; 25 men) with known ischemic cardiomyopathy and impaired LV systolic function, one-directional time-resolved VE MRI was performed on 1.5T MRI (Philips) to acquire the LV inflow pattern. A 4-chamber orientation was chosen with inplane velocity-encoding in phase encoding (=long-axis) direction and velocity sensitivity $20 \mathrm{~cm} / \mathrm{s}$. Effective temporal resolution of $6.5 \mathrm{~ms}$ (true temporal resolution $2 \times \mathrm{TR}=13 \mathrm{~ms}$ ) was achieved. The LV inflow pattern was sampled at the position of the mitral valve (MV) and at a location approximately $4 \mathrm{~cm}$ distally, with regions-ofinterest (ROIs) aligned along the visually-assessed inflow direction (Figure 1A). The inflow velocity-time curves were constructed from the mean velocities per cardiac phase sampled in each of these ROIs (size typically $2 \mathrm{~mm}^{2}$ ) (Figure 1B). Phase unwrapping was used for aliasing correction. Early peak filling (Epeak) velocity was determined

${ }^{1}$ Radiology, Leiden University Medical Center, Leiden, the Netherlands Full list of author information is available at the end of the article from the velocity sampled at the MV. The time-to-peak inflow velocity was determined from the velocity-time curves, and the distance between ROIs $(\Delta x)$ and the difference in time-to-peak velocity $(\Delta \mathrm{t})$ defined $\operatorname{Vprop}(=\Delta \mathrm{x} / \Delta \mathrm{t})$.

For comparison purpose, patients underwent echocardiography within the same week of MRI to assess Vprop by Color M-mode echo Doppler as previously described [1]. Vprop from VE MRI was compared with echo Doppler, using paired t-test and Pearson correlation. When using a cut-off value for Vprop of $45 \mathrm{~cm} / \mathrm{s}$ to classify diastolic dysfunction [1], a cross-table was constructed to determine weighted kappa agreement between both modalities.

\section{Results}

Assessment of Vprop from VE MRI showed good correlation with echo Doppler with Pearson $R=0.71$ ( $p<0.001$ ). A small statistically non-significant overestimation was present on VE MRI compared to echo Doppler of $3 \pm 24 \mathrm{~cm} / \mathrm{s}(\mathrm{p}=0.40)$. Vprop was not statistically significant correlated with Epeak velocity (Pearsons $\mathrm{R}=0.14, \mathrm{p}=0.41$ ), both assessed with VE MRI.

VE MRI and echo Doppler showed good agreement (kappa 0.72), with sensitivity/specificity of $84 \% / 82 \%$ for diastolic function classification by Vprop.

\section{Conclusions}

VE MRI and Color M-mode echo Doppler showed good correlation and agreement for Vprop-assessment in ischemic cardiomyopathy regardless of LV inflow velocity, with a high sensitivity and specificity for VE MRI classifying diastolic dysfunction. 

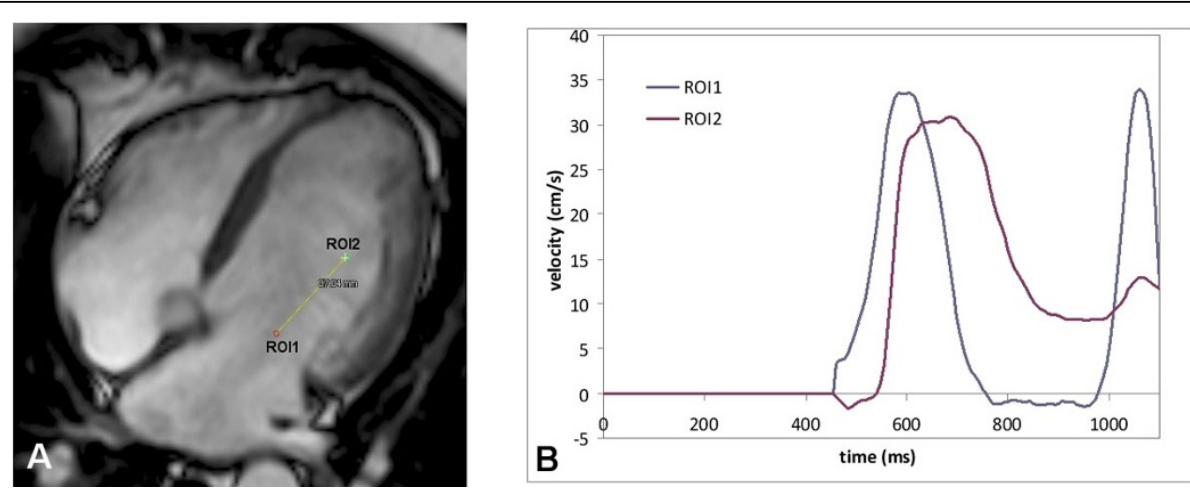

Figure 1 Example of Vprop-assessment with VE MRI. Regions-of-interest (ROIs) were positioned in a 4-chamber view at the mitral valve (ROI1) and at $37 \mathrm{~mm}$ distal to the valve (ROI2), aligned along the direction of the inflow (A). Velocity was sampled at both ROls and velocity-time curves were constructed (B). Inflow propagation was determined from the propagation of the Epeak.

Table 1 Diastolic dysfunction classification using Vprop $<45 \mathrm{~cm} / \mathrm{s}$ as cut-off criterion.

\begin{tabular}{cccc}
\hline & \multicolumn{3}{c}{ Echo } \\
\cline { 2 - 4 } & $\leq 45 \mathrm{~cm} / \mathrm{s}$ & $>45 \mathrm{~cm} / \mathrm{s}$ & \\
\hline \multirow{3}{*}{ MRI } & $\leq 45 \mathrm{~cm} / \mathrm{s}$ & 21 & 2 \\
& $>45 \mathrm{~cm} / \mathrm{s}$ & 4 & 9 \\
\hline
\end{tabular}

\section{Funding}

STW project 11626.

\section{Author details}

${ }^{1}$ Radiology, Leiden University Medical Center, Leiden, the Netherlands.

${ }^{2}$ Cardiology, Leiden University Medical Center, Leiden, the Netherlands.

Published: 30 January 2013

\section{Reference}

1. Garcia MJ.: J Am Coll Cardiol 1998

doi:10.1186/1532-429X-15-S1-P54

Cite this article as: van den Boogaard et al: Left ventricular inflow propagation velocity for diastolic function testing: head-to-head

comparison between velocity-encoded MRI and color M-mode Doppler echocardiography. Journal of Cardiovascular Magnetic Resonance 201315

(Suppl 1):P54

Submit your next manuscript to BioMed Central and take full advantage of:

- Convenient online submission

- Thorough peer review

- No space constraints or color figure charges

- Immediate publication on acceptance

- Inclusion in PubMed, CAS, Scopus and Google Scholar

- Research which is freely available for redistribution

Submit your manuscript at www biomedcentral.com/submit 